\title{
Crosslinking chemistry for high-performance polymer networks*
}

\author{
Kenneth A. Walkerț, Larry J. Markoskił, Gary A. Deeterț, \\ Gary E. Spilman§, David C. Martin $\nmid \S$ and Jeffrey S. Moore** \\ $\ddagger$ Department of Chemistry, §Macromolecular Science and Engineering Center, and \\ T Department of Materials Science and Engineering. The University of Michigan, \\ Ann Arbor, MI 48109, USA \\ ** Department of Chemistry, The University of Illinois at Urbana-Champaign, Urbana, \\ IL 61801, USA
}

\begin{abstract}
A new thermally reactive monomer has been designed and synthesized that brings novel crosslinking chemistry to high-performance polymers. This monomer (XTA) is a derivative of terephthalic acid and was based on the thermal chemistry of benzocyclobutene. Various model compounds have been synthesized to investigate substituent effects on benzocyclobutene reactivity. Irreversible reaction exotherms around $350^{\circ} \mathrm{C}$ were observed in these model compounds using differential scanning calorimetry. Based on these studies, polyaramid and poly(aryl ether ketone) XTA copolymers were synthesized. The formation of an insoluble network resulted after heat treatment of these polymers.
\end{abstract}

(Keywords: crosslinking; benzocyclobutene; polyaramid)

\section{INTRODUCTION}

Crosslinked polymers are increasingly used as engineering materials because of their excellent stability toward elevated temperatures and mechanical deformation. Traditional crosslinking chemistry for step-growth polymers involves polycondensation with multifunctional monomers, so that the same chemical reactions are used for chain growth and network formation. The molecular weight of these systems is thus directly coupled to the percentage of functional group conversion. Consequently, all processing must be done prior to gelation, at which point the final network is obtained by driving the polycondensation reaction to higher extent of conversion. Even when the overall functional group stoichiometry is balanced, it is rare that complete conversion is obtained. Defect structures resulting from intramolecular cyclization and unreacted chain ends are therefore common. Thus, traditional crosslinking chemistry leads to poorly defined networks that have considerable processing limitations.

Many of these disadvantages can be overcome by designing reactive monomers which allow linear chain growth and crosslinking to take place under unique conditions. The advantages come from the fact that the crosslink density, and therefore the gelation point, is no longer coupled to the degree of conversion. This in turn leads to greater processability since high molecular weight polymers can first be prepared and fabricated into their desirable form. Crosslink density in these polymers is simply controlled by the percentage of reactive comonomer. Defect structures are minimized since high

\footnotetext{
* Presented at the American Chemical Society, Division of Polymer Chemistry ' 17 th Biennial Symposium on Advances in Polymerization and High Performance Polymeric Materials', 22-25 November 1992, Palm Springs, CA, USA

† To whom correspondence should be addressed

0032-3861/94/23/5012-06

c. 1994 Butterworth-Heinemann Ltd
}

5012 POLYMER Volume 35 Number 231994 molecular weight linear polymers are fully formed prior to introduction of crosslinks.

Design of a new monomer should be carried out with several criteria in mind. First, incorporation of this comonomer into polymer backbones should not dramatically alter present methods employed for polymer synthesis or processing. Polymer chains thus need to be equipped with a reactive group that lies dormant throughout the synthesis and initial stages of processing but which can be triggered into a reactive state at some later time. Crosslinking should occur without evolution of volatile by-products so as to minimize volume changes during curing. The crosslinking chemistry should involve a highly reactive intermediate in order to allow solid-state curing and to minimize unreacted functionality. The ideal comonomer should be easily synthesized and offer a wide variety of polycondensation chemistry.

\section{RESULTS AND DISCUSSION}

\section{Monomer design and synthesis}

With these ideas in mind, we set out to design a reactive monomer that had the versatility to be incorporated into several different high performance polymer backbones. Our approach involved structural unit $\mathbf{1}$, containing the benzocyclobutene (BCB) moiety which has been shown to be a thermally crosslinkable group ${ }^{1-8}$.

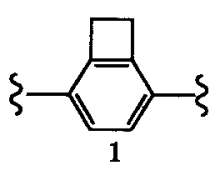

At elevated temperatures, the cyclobutene ring opens to generate the reactive ortho-quinodimethane intermediate, which is capable of hetero-cycloaddition chemistry if 
suitable dienophiles are available (for a recent example of a monofunctional BCB monomer that undergoes thermal Diels-Alder polymerization, see ref. 9). In the absence of dienophiles, ortho-quinodimethanes will undergo cyclodimerization ${ }^{10}$ followed by a cascade of reactions that ultimately lead to poly(ortho-xylenes) or dibenzocycloocta-1,5-dienes (for a recent review on the chemistry of orthoquinodimethanes, see ref. 11). Thus, the anticipated crosslinking reactions should not result in a change in mass. The difference between 1 and previous polymers involving $\mathrm{BCB}$ chemistry is that the cyclobutaarene ring of $\mathbf{1}$ is incorporated directly into the polymer backbone instead of being used as an end group or as a pendent group.

Symmetrical disubstitution of the parent hydrocarbon, benzocyclobutene, in the 2 - and 5 - positions could readily be accomplished using the procedure first described by Kundig et al. ${ }^{12}$. Thus, reductive silylation of BCB followed by air oxidation gives the crystalline 2,5bis(trimethylsilyl)benzocyclobutene intermediate 2 .

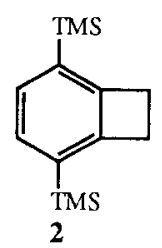

Recognizing the value of this intermediate as a precursor to a variety of monomers for 1 , we have developed improved procedures amenable to scale-up for obtaining 2 . While Kundig's reductive silylation proceeded as described, we found that for largescale work the reaction could be more conveniently carried out using preparative electrochemistry ${ }^{13}$. Using a constant current source, a consumable aluminium anode, and a carbon cloth cathode, high yield of the dihydrobenzene has been obtained:
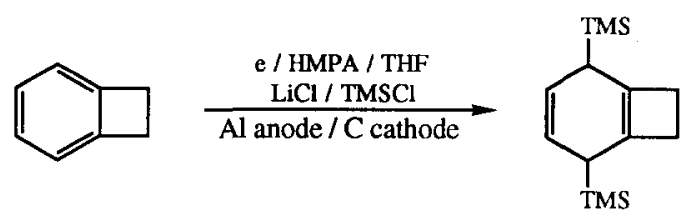

Re-aromatization of the resulting dihydrobenzene proceeded erratically, as originally described, and became especially troublesome on larger scales. The original procedure simply involved bubbling air through a rapidly stirred toluene solution. We explored the use of oxidation reagents such as 2,3-dichloro-5,6-dicyano-1,4-benzoquinone and tetrachloro-1,4-benzoquinone. Although moderately successful, these reagents were difficult to remove, were required in large molar excess to be effective, and were expensive for large-scale preparations. We then discovered that aromatization of the dihydrobenzene intermediate proceeded smoothly and conveniently simply by changing the solvent from toluene, as originally described, to dimethylsulfoxide ${ }^{14}$. Under these conditions, crystals of 2 precipitate from solution and the reaction was complete in $24-36 \mathrm{~h}$.

The widespread use of terephthalic acid in step-growth polymerizations led us to prepare the analogous aromatic diacid structure incorporating the BCB moiety. We have previously described a high yield preparation of 3 , which we call XTA, in three steps from $2^{14}$. The preparation gives pure XTA in an overall yield of $70 \%$ based on BCB.<smiles>O=C(O)c1ccc(C(=O)O)c2c1CC2</smiles>

The corresponding diacid chloride can be prepared by standard methods and gives a white crystalline solid suitable for polycondensation following sublimation and recrystallization.

\section{Model compounds of XTA}

To test the reactivity of the cyclobutaarene ring, a number of derivatives of $\mathbf{3}$ were prepared (see equations (2) and (3) $)^{14,15}$. Surprisingly, the bisbenzthiazol derivative 6 could be prepared in high yield under rather harsh conditions involving polyphosphoric acid, high temperature and extended periods of time. This result provided the first clue as to the thermal and chemical stability of the 2,5-substituted cyclobutaarene ring. Similarly, ${ }^{1} \mathrm{H}$ n.m.r. was used to show that the cyclobutaarene ring of bisamide 5 remained intact in concentrated $\mathrm{D}_{2} \mathrm{SO}_{4}$. This exceptional stability opens up many possibilities for polymer synthesis and processing without disturbing the latent reactivity of the $\mathrm{BCB}$ ring. Differential scanning calorimetry (d.s.c.) traces of these derivatives are shown in Figure 1. These experiments show that at temperatures above $350^{\circ} \mathrm{C}$, an irreversible exotherm is observed $\left(\Delta H=20 \mathrm{kcal} \mathrm{mol}^{-1}\right)$, which presumably corresponds to the reaction of the orthoquinodimethane intermediate. In the case of the derivative 6 , the reaction occurs well above the reversible melting transition. We note that the chemical and thermal stability of these 2,5-disubstituted BCBs is much greater than many of the other previously reported $\mathrm{BCB}$ derivatives, all of which were substituted at the 3-position.

These trends have been borne out by further studies on the series of model compounds shown in Table 1.
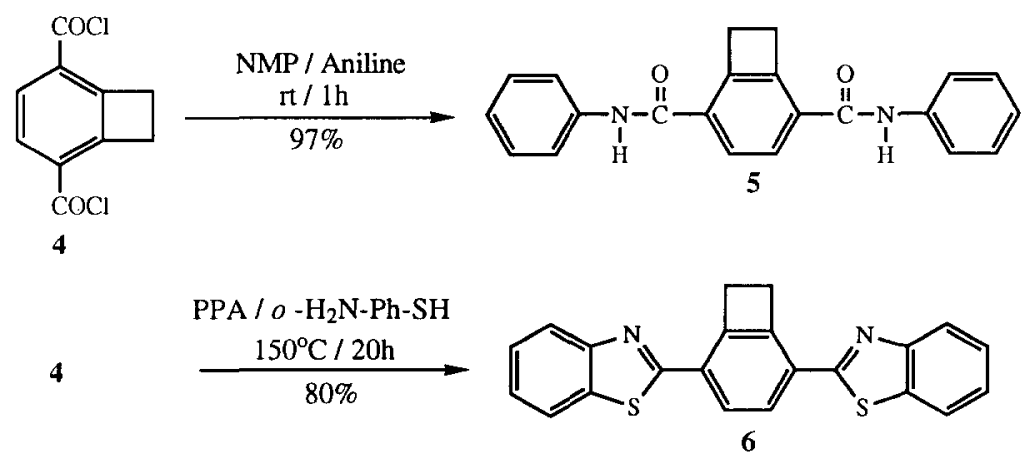


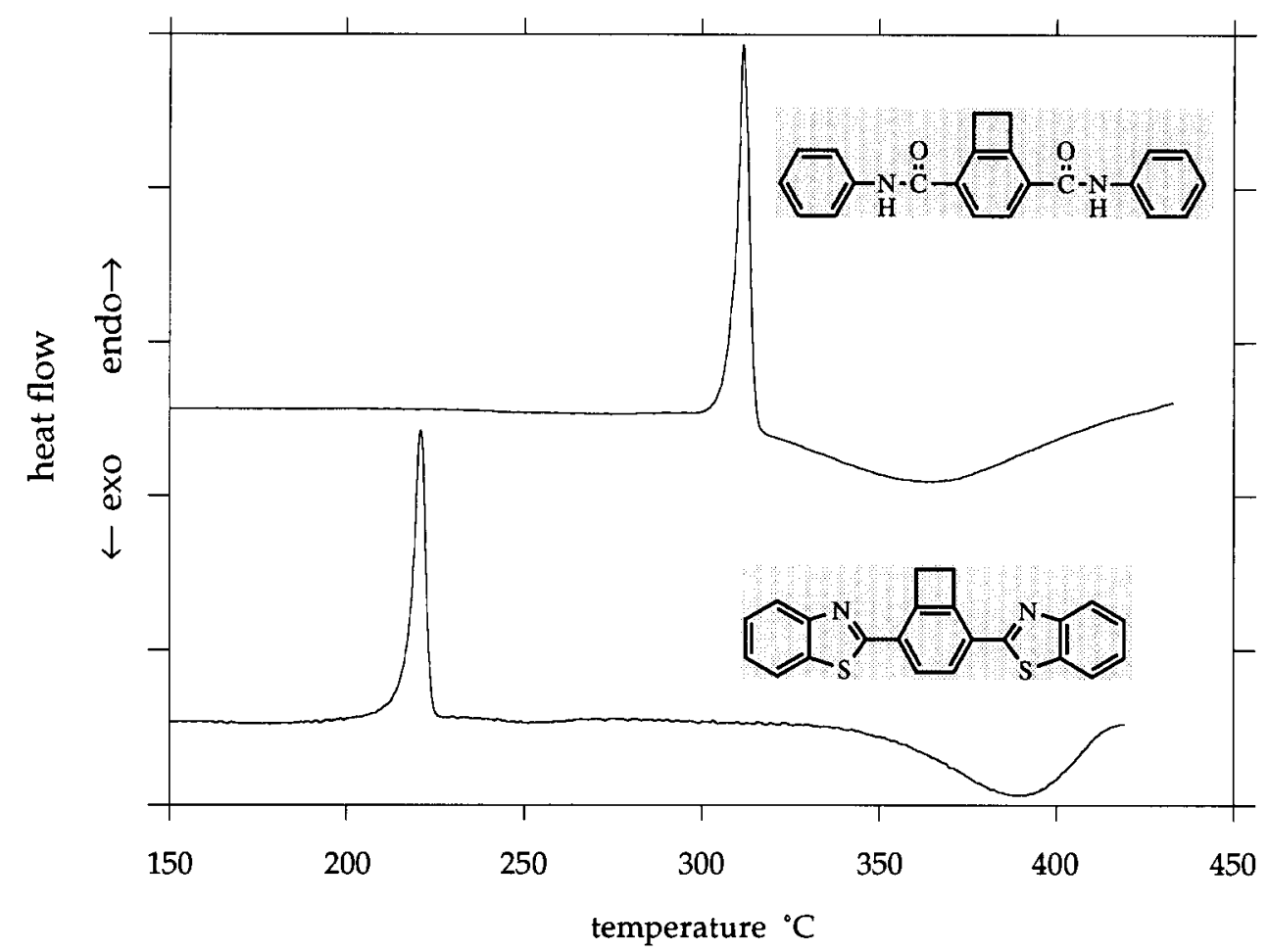

Figure 1 D.s.c. traces of model compounds 5 and 6 at a heating rate of $10^{\circ} \mathrm{C} \mathrm{min}-1$

Table 1 Model compounds derived from 2 and their thermal analysis data

\begin{tabular}{llll}
\hline \multirow{2}{*}{ Model compound } & $\begin{array}{c}T_{\text {melt }} \\
\left({ }^{\circ} \mathrm{C}\right)\end{array}$ & $\begin{array}{l}T_{\text {rxn }} \\
\left({ }^{\circ} \mathrm{C}\right)\end{array}$ & $\begin{array}{l}\Delta H_{\mathrm{rxn}} \\
\left(\mathrm{kcal} \mathrm{mol}^{-1}\right)\end{array}$ \\
\hline
\end{tabular}<smiles>O=C(Nc1ccccc1)c1ccc(C(=O)Nc2ccccc2)c2c1CC2</smiles><smiles>c1ccc2oc(-c3ccc(-c4nc5ccccc5o4)c4c3CC4)nc2c1</smiles><smiles>O=[W]1CCCC1</smiles>

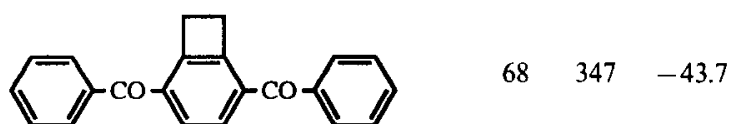<smiles>O=C(Oc1ccccc1)c1ccc(C(=O)c2ccccc2)c2c1CC2</smiles><smiles>C(#Cc1ccc(C#Cc2ccccc2)c2c1CC2)c1ccccc1</smiles><smiles>C(#Cc1ccccc1)Oc1ccc(C#Cc2ccccc2)c2c1CC2</smiles>

In most cases, the exothermic reaction ensues at a temperature greater than $300^{\circ} \mathrm{C}$, with the exception being model compounds that contain dienophiles. Interestingly, there is good correlation between the heat of reaction and the reaction temperature, with higher temperatures corresponding to smaller energies. These findings suggest that when dienophiles are present, the ortho-quinodimethane intermediate undergoes facile $(4+2)$ cycloaddition reaction. In the absence of a dieneophile, this intermediate is apparently more stable, but it eventually reacts, perhaps by dimerization. Investigations on the chemical structure of these reaction products are in progress.

\section{Aramid copolymers containing $X T A$}

Encouraged by the d.s.c. data of the model compounds, we initiated research on the synthesis of high performance extended chain and rigid-rod polymers incorporating structural unit 1 . We hoped this modification would address two deficiencies that currently limit the use of these materials in structural applications. One limitation is that fibres of polymers such as poly( $p$-phenylene terephthalamide) (PPTA or Kevlar $\left.{ }^{(\mathbb{B}}\right)$, poly $\{$ (benzo- $[1,2-$ d;4,5-d']-bisthiazole-2,6-diyl)-1,4-phenylene $\}$ (PBZT), and poly\{(benzo-[1,2-d;4,5-d']-bisoxazole-2,6-diyl)-1,4-phenylene (PBZO), while extremely stiff and strong in tension, are relatively weak in compression ${ }^{16,17}$. The weakness in compression is presumably due, at least in part, to the ease of buckling of individual molecules or microfibrils resulting from the lack of strong lateral interchain interactions ${ }^{17}$. The addition of transverse covalent bonding might improve the compressive strength of these fibres. A second area of improvement would be to enhance interfacial strength between these fibres and composite matrices. The possibility of the latent reactivity in these fibres that could be triggered during matrix curing may 


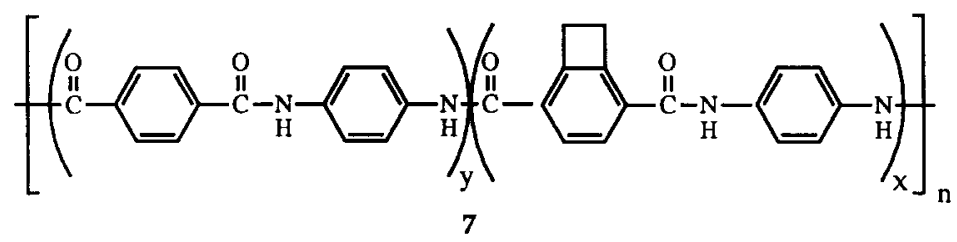

lead to chemical bonding and thus improved adhesion between components.

To test some of these ideas, we prepared copolymers of PPTA incorporating various XTA contents $(7)^{18}$. These studies show that high molecular weight copolymers incorporating XTA over a full range of proportions could be prepared using low temperature polycondensation reactions. Dilute solution viscosity and ${ }^{1} \mathrm{H}$ n.m.r. characterization in $98 \%$ sulfuric acid confirm the chemical structure and high molecular weight of these copolymers. At high concentrations (e.g. $20 \mathrm{wt} \%$ ) in $100 \%$ $\mathrm{H}_{2} \mathrm{SO}_{4}$, birefringent fluids are observed, even for the polymer having an XTA composition of $100 \%$. The copolymers can be crosslinked in the solid state by brief heat treatment in nitrogen at $400^{\circ} \mathrm{C}$. The crosslinking reaction has been monitored by d.s.c. (see Figure 2), which shows that the enthalpy of this reaction varies linearly with mole per cent XTA $\left(\Delta H \approx 8.0 \mathrm{kcal} \mathrm{mol}^{-1}\right.$ of XTA) (see Figure 2 inset). Solubility experiments confirm that crosslinking occurs even for copolymers containing only $1 \mathrm{~mol} \%$ XTA. These lightly crosslinked materials swell into an optically transparent yellow gel in concentrated sulfuric acid. In contrast, similarly heattreated homopolymer containing no XTA can be fully dissolved. Thermogravimetric analysis shows that less than $2 \%$ mass loss accompanies the crosslinking reaction. The preparation of fibres of these reactive copolymers is in progress.

\section{Crosslinkable poly(arylene ether ketone)s}

Poly(arylene ether ketone)s and the related poly(arylene ether sulfone)s generally have low flammability, good resistance to strong chemicals, stability up to moderately high temperatures, and can be fabricated using conventional polymer processing methods ${ }^{19}$. Commercially available examples are Udel [poly(ether sulfone) (Amoco)] and PEEK [poly(ether ether ketone) (ICI)]. These materials are high-performance engineering thermoplastics and are

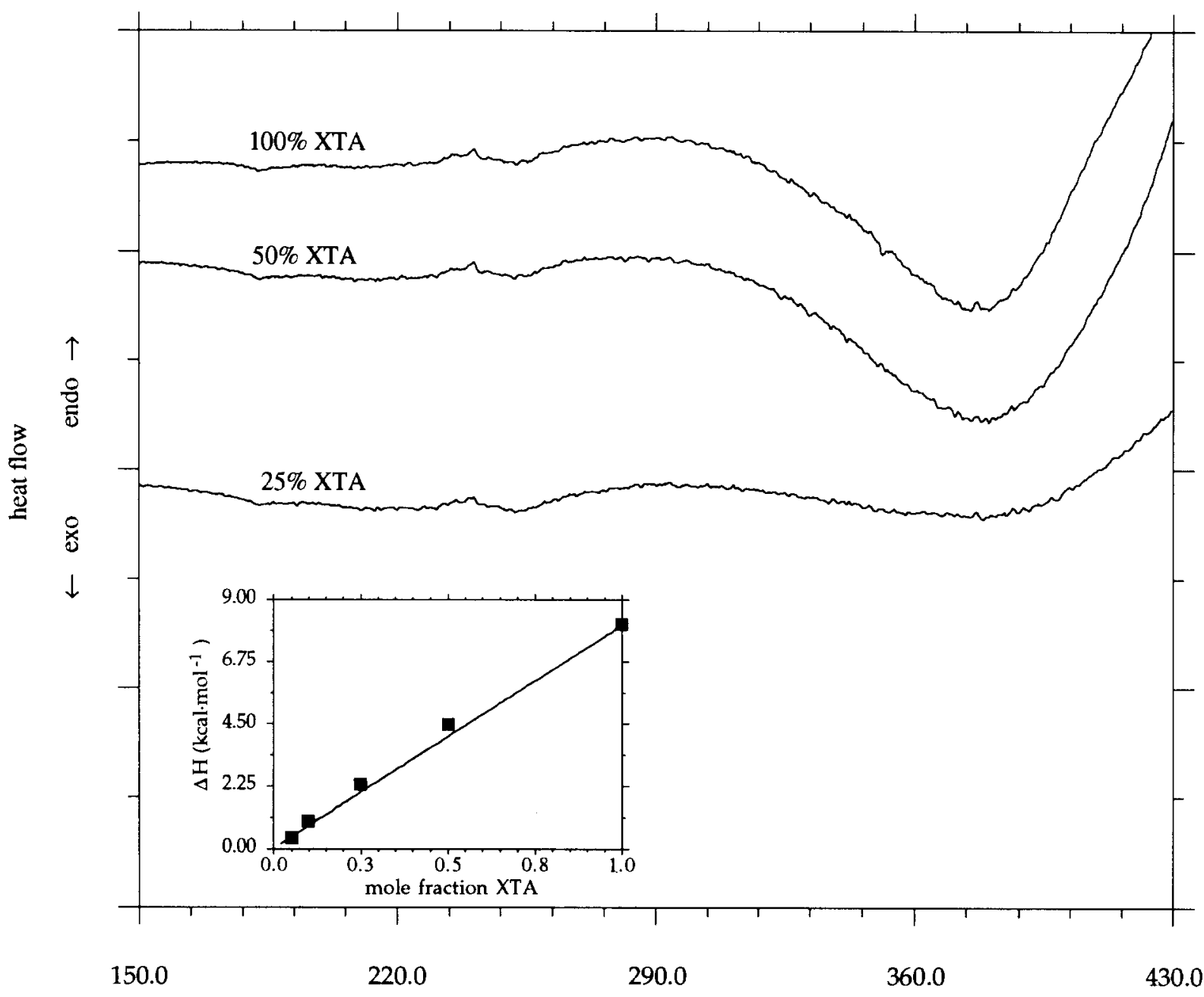

temperature ${ }^{\circ} \mathrm{C}$

Figure 2 Representative d.s.c. traces of PPTA copolymers containing XTA at a heating rate of $10^{\circ} \mathrm{C} \mathrm{min}^{-1}$. The inset shows plot of the enthalpy cersus XTA content of the crosslinking reaction 


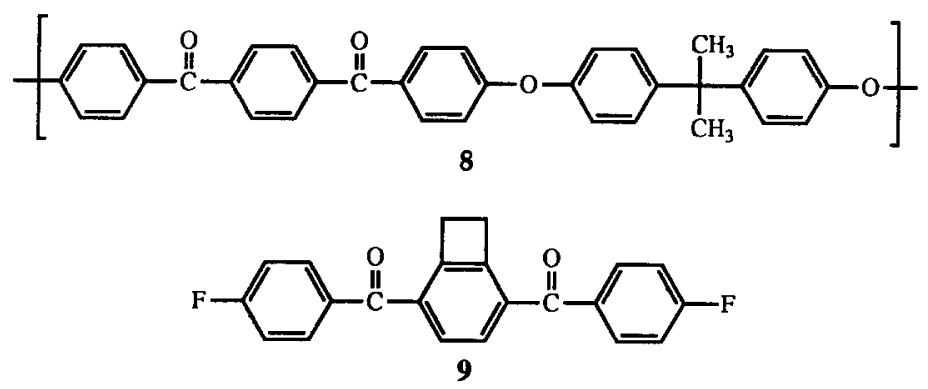

used in applications such as coatings, adhesives and structural composites. These compounds can exist as either semicrystalline or totally amorphous solids, each with distinct properties. Semicrystalline poly(arylene ether ketone)s have high chemical resistivity and excellent thermal stability, but can be difficult to process. Their amorphous analogues, on the other hand, are more easily processed but have correspondingly diminished properties. One way to combine the advantages of both would be to first process amorphous polymers that could later be crosslinked to a high performance network.

Polymer $\mathbf{8}$ is an amorphous engineering resin (glass transition temperature $=160^{\circ} \mathrm{C}$ ) with mechanical properties similar to those of poly(ether sulfone) but with an extraordinarily high elongation at break $(150 \%)$. In addition, the polymer has high transparency, high

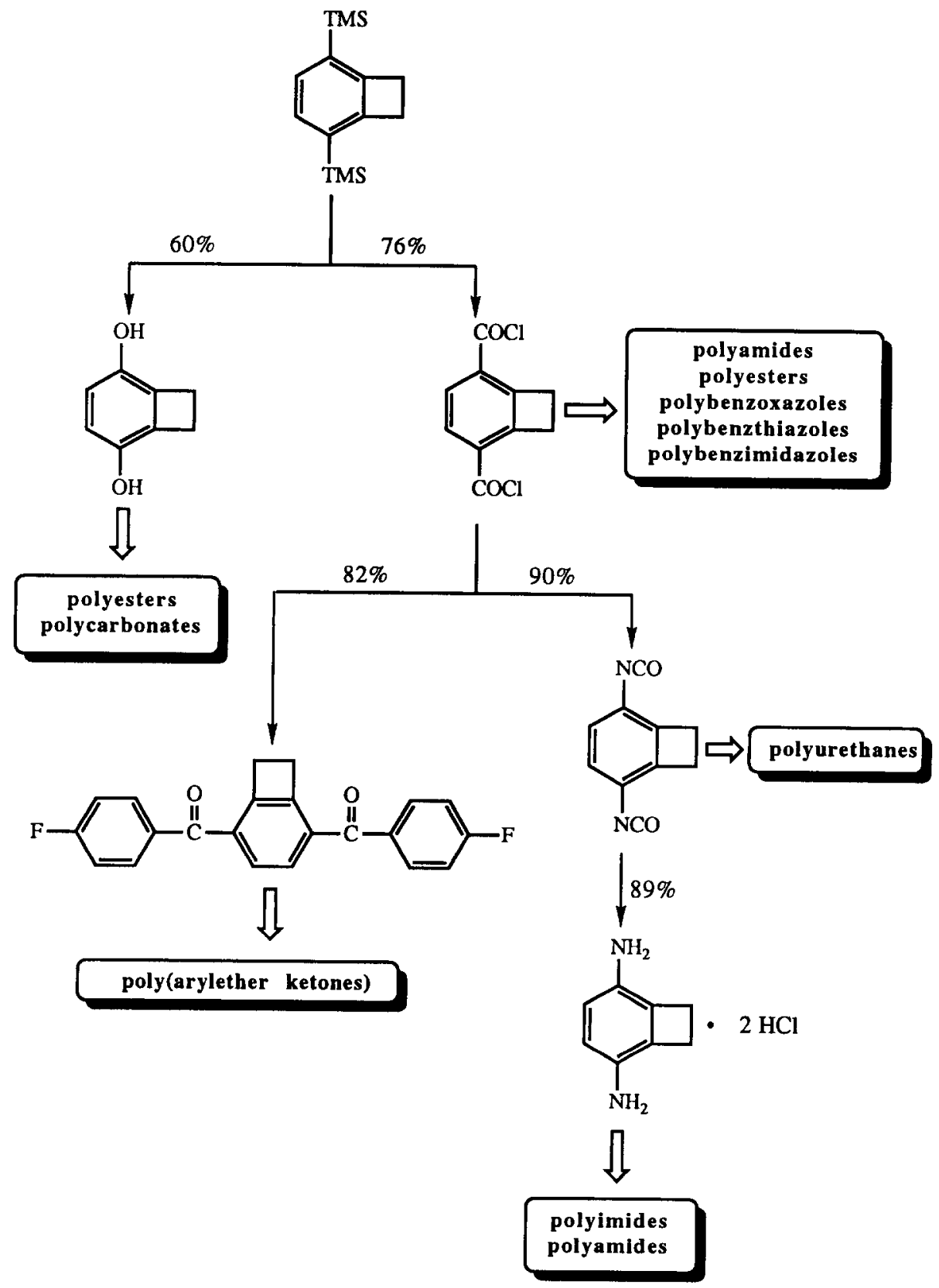

Scheme 1 BCB monomers from 2 


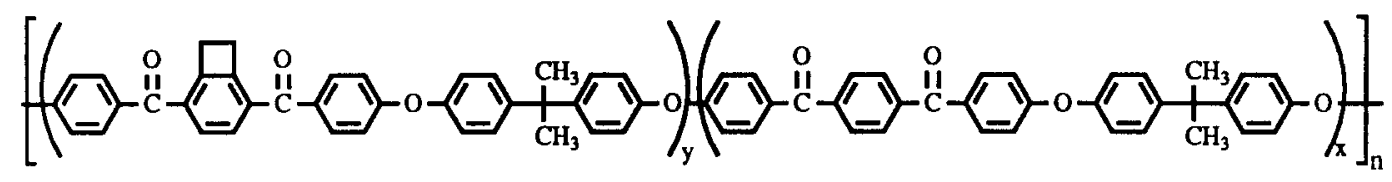

refractive index (1.664), low density $\left(1.2 \mathrm{~g} \mathrm{~cm}^{-3}\right)$, and low water adsorption, making this material a candidate for optical applications ${ }^{20}$. We are interested in the development of amorphous copolymers based on $\mathbf{8}$, that can be thermally crosslinked to materials that have similar properties to semicrystalline poly(arylene ether ketone)s. These polymers should still possess the advantages of easy processing characteristic of the amorphous poly(arylene ether ketone)s. For this purpose, we synthesized the thermally reactive monomer $\mathbf{9}$, designed to lie dormant throughout synthesis and processing, but then be triggered to a reactive state at some later point. Monomer 9 was readily prepared by Friedel Crafts acylation of fluorobenzene and $\mathbf{4}$.

High molecular weight copolymers containing 9, 1,4bis(4-fluorobenzoyl)-benzene, and 4,4-isopropylidenediphenol (Bisphenol A) were synthesized by standard solution polycondensation ${ }^{21}$. Soluble, amorphous polymers were obtained and no evidence of crosslinking occurred during the polymerization reaction, provided that the temperature was maintained below $150^{\circ} \mathrm{C}$. The polymers were characterized by gel permeation chromatography and by ${ }^{1} \mathrm{H}$ and ${ }^{13} \mathrm{C}$ n.m.r. The copolymers can be crosslinked well above their glass transition temperature by brief treatment in nitrogen at $400^{\circ} \mathrm{C}$. The crosslinking reaction was monitored by d.s.c., which showed that the heat of the reaction was proportional to BCB content. The resulting networks were insoluble in all solvents including concentrated sulfuric acid. Thermogravimetric analysis showed that no significant mass loss accompanied the crosslinking reaction. Mechanical properties of these networks are currently being studied.

\section{New monomers derived from $B C B$}

Bis(trimethylsilyl) derivative 2 has proven to be an extremely valuable intermediate. We have completed exploratory synthetic chemistry starting from 2 leading to a diverse collection of aromatic monomers. Scheme 1 shows the synthetic tree of monomers and potential polymers. The only polymers we have prepared to date are the aramids derived from 4 and the poly(arylene ether ketone)s derived from 9 . However, these two polymeric examples and the model compound studies suggest that 2,5-disubstituted benzocyclobutenes have a wide operating window for synthesis and processing. We anticipate that this chemistry may find use in the synthesis of other high-performance polymer networks.

\section{ACKNOWLEDGEMENTS}

This research is funded by the US Army (DAAK6092-K-0005). D.C.M. acknowledges support from the NSF Young Investigator Program (1992-1997). J.S.M. acknowledges the $3 \mathrm{M}$ company for support through their awards programme for untenured faculty and the NSF Young Investigator Program (1992-1997). James Markoski is thanked for help in the design and construction of the polymerization apparatus.

\section{REFERENCES}

1 Kirchhoff, R. A., Carriere, C. J., Bruza, K. J., Rondan, N. G. and Sammler, R. L. J. Macromol. Sci., Chem. 1991, A28, 1079

2 Upshaw, T. A., Stille, J. K. and Droske, J. P. Macromolecules $1991,24,2143$

3 Tan, L. S. and Arnold, F. E. Polvm. Prepr. Ant. Chem. Soc. Dit. Polym. Chem. 1991, 32 (1), 636

4 Chuah, H. H., Tan, L. S. and Arnold, F. E. Polyn. Eng. Sci 1989, 29 (2). 107

5 Tan, L. S., Arnold, F. E. and Soloski, E. J. J. Polym. Sci. Part A: Pollm. Chem. 1988, 26, 3103

6 Tan. L. S. and Arnold, F. E. J. Polym. Sci., Part A: Polım Chem. 1988, 26, 1819

7 Tan. L. S., Soloski, E. J. and Arnold. F. E. Am. Chem. Soc Sinip. Ser. 1988, 367, 349

8 Tan. L. S. and Arnold, F. E. J. Polım. Sci., Part A: Polım Chem. 1987, 25, 3159

9 Hahn, S. F., Martin, S. J. and McKelvy, M. L. Macromolecules $1992,25,1539$

10 Errede, L. A. J. Am. Chem. Soc. 1961, 83, 949

11 Martin, N., Seoane, C. and Hanack, M. Org. Prep. Proc. Int 1991, 23, 237

12 Kundig, E. P., Perret, C. and Rudolph, B. Helt. Chim. Acta $1990,73,1970$

13 Spilman, G. E. and Moore, J. S. unpublished results, 1993

14 Walker, K. A., Markoski, L. J. and Moore, J. S. Sinthesis 1992 1265

15 Deeter, G. A. and Moore, J. S. unpublished results, 1993

16 Allen, S. R. J. Mater. Sci. 1987, 22,853

17 Martin, D. C. and Thomas, E. L. J. Mater. Sci. 1991, 26, 5171

18 Markoski, L. J., Walker, K. A., Deeter, G. A., Spilman, G. E., Martin, D. C. and Moore, J. S. Chem. Mater. 1993, 5, 248

19 May, R. in 'Encyclopedia of Polymer Science and Engineering', (Eds H. F. Mark, N. M. Bikales, C. G. Overberger, G. Menges and J. I. Kroschwitz), Wiley, New York, 1988, Vol. 12, p. 313

20 Herold, F. and Schneller, A. Adr. Mater. 1992, 4, 143

21 Walker, K. A., Markoski, L. J. and Moore, J. S. Macromolecules $1993,26,3713$ 